\title{
The Exposure of Counseling Practicum Students to Humanistic Counseling Theories: A Survey of CACREP Programs
}

\author{
TREY J. FITCH \\ RICHARD CANADA \\ JENNIFER L. MARSHALL
}

\begin{abstract}
Counseling theories applied in initial clinical training courses (practicum) influence the counselors-in-training's future practice of counseling. Results of this study indicated that humanistic models are influential in current counseling practicum courses and will maintain a strong influence in the future.
\end{abstract}

Freeman and McHenry (1996) emphasized the role that theory plays in counselor training and education. More than 400 counseling theories exist (Corsini, 1996), and selecting theories for application in clinical counseling training courses is difficult. Process and conceptualization skills (Bernard \& Goodyear, 1992) are both linked to the theory a counselor-in-training chooses to use with clients. The theories that counselor educators choose to teach in clinical practicum courses greatly influence the practice and orientation of the counselors-in-training. Practicum courses are defined here as the initial clinical training course when students begin counseling with clients. Several authors have indicated that the client-counselor relationship is more significant in positive counseling outcomes than are the techniques and models used (Brammer \& MacDonald, 1999; Capuzzi \& Gross, 1999; Cormier \& Hackney, 1999). Because humanistic theories tend to emphasize client-counselor relationship variables more than most other models do, they should be especially relevant for use in clinical training. Humanistic theories that are frequently used today are person-centered counseling and Gestalt therapy. Both of these theories grew from existentialism-the belief that innate growth, choice, values, responsibility, and meaning are major concepts of counseling.

Trey J. Fitch is an assistant professor of counseling in the Department of Leadership and Secondary Education at Morehead State University, Morehead, Kentucky. Richard Canada is a professor of counseling in the Department of Professional Studies at Texas A\&M University-Corpus Christi. Jennifer L. Marshall is the director of counseling at Berea College, Berea, Kentucky. Correspondence regarding this article should be sent to Trey J. Fitch, 503 Ginger Hall, Morehead State University, Morehead, KY 40351 (e-mail: t.fitch@morehead-st.edu). 
The purpose of this study was to identify the prevalence of teaching and applying humanistic approaches in counseling practicum courses accredited by the Council for Accreditation for Counseling and Related Educational Programs (CACREP). Another purpose of the study was to compare the prevalence of humanistic theories taught in relation to other major forces of counseling, specifically psychodynamic and behavioral models. The current study seeks to validate or dispute the findings from Freeman and McHenry's (1996) study and to discover any new trends, especially regarding humanistic theory.

\section{THE THREE FORCES IN COUNSELING THEORY}

Nugent (2000) outlined three major forces in counseling theory. The forces have been cited as psychoanalytic, behaviorism, and humanistic counseling. These trends in counseling theory reflect major shifts in the perceived goals of counseling, the methods taught, and the main focus of counseling. For example, psychoanalytic counselors are trained to tap into the unconscious, whereas behavioral counselors focus on learning more adaptive responses. Humanistic counselors stress the significance of affect, selfunderstanding, and enhanced awareness. The future popularity of any of the three approaches can be partially anticipated by examining what theories counselor educators currently apply in clinical training courses. Proponents of humanistic models can anticipate the future strength and influence of these approaches by exploring the history of humanistic theories and the theoretical trends in counseling practicum courses.

Although debate exists regarding the classification of theories, traditionally there have been three approaches classified as humanistic. According to Nugent (2000), they are (a) person-centered, (b) Gestalt, and (c) existential. However, existentialism is better defined as a philosophy that influences humanism rather than a distinct theory. Because some respondents listed existentialism as a theory applied in their practicum courses, it was listed as a separate theory on the survey. However, the real influence of existentialism is seen in its influence on humanistic theory. For the purpose of this study, the aforementioned theories are classified as humanistic; however, some authors might also include Rational Emotive Behavior Therapy (REBT), as well as other theories.

\section{HISTORICAL ROOTS OF HUMANISTIC THEORY}

Humanistic theory centers on the belief that human nature is basically positive and that individuals possess the skills to direct their own behavior in a purposeful and meaningful direction. This direction is maintained through an individual's power of using free choice (Nugent, 2000). These theories also focus on "the client-therapist relationship, the client's perceptions, and the call for the therapist to enter the client's subjective world" 
(Corey, 1996, p. 200). Humanistic counselors are primarily facilitators whereas behavioral counselors are more didactic and directive. Whereas psychoanalytic counselors and humanistic counselors view the counseling relationship as significant, the behavioral counselors promote a collaborative and equal relationship.

\section{Person-Centered Theory}

Rogers was the originator of person-centered (client-centered) theory. This theory focuses on the therapeutic relationship in which the therapist helps the client achieve insight, independence, and development through the client's innate drive for growth and wholeness. Rogers is a proponent of the argument that every individual has a basic need for personal growth through life experiences. These integrated experiences, if unhampered by unhealthy social and psychological influences, can lead the individual to self-actualization. Self-actualization is defined as the process of change in which an individual grows through experiences to reach a total fulfillment and completeness with themselves and their life (Rogers, 1942, 1951).

Rogers (1942) was influenced by relationship therapy that was developed by Rank (1936). This type of therapy did not use the traditional psychoanalysis interpretation or judgments regarding the client's condition. Instead, it focused on how the client might benefit through the clienttherapist relationship. This influential experience led to the evolution of nondirective counseling, which later became client-centered (person-centered) theory. In contrast to his predecessors, Rogers used his therapy to focus more on the individual than on the individual's problems. This focus led him to believe that diagnosing a problem might indicate the symptom but not explain the cause of the symptom (Rogers, 1939). Rogers also pioneered a revolution regarding the nature of the counseling relationship. Freud's emphasis on developing a transference relationship promoted a neutral, distant analyst. In great contrast, Rogers sought emotional connectedness with clients and emphasized counselor warmth and congruence.

Rogers's work on person-centered theory has been a crucial part of the history of counseling. This theory, which is easily applicable to counseling well-adjusted people with typical developmental problems, can be used with traditional psychotherapy and vocational guidance as well as in educational settings. It has made today's therapists focus more on the counseling relationship and the therapeutic experience of the whole process of counseling (Nugent, 2000).

\section{Existential Theory}

Existentialism's foundation goes back to the roots of the European philosophies of Heidegger, Kierkegaard, and Sartre (Gladding, 1988). These philosophies have been carried to the United States and applied to 
counseling practice by May (1961), Yalom (1980), and Frankl (1963). The focus of this philosophy, which underlies many humanistic theories, is on values, meaning, and responsibility. This philosophy has counselors "ask deep questions about the nature of the human being and the nature of anxiety, despair, grief, loneliness, and anomie" (May \& Yalom, 1995, p. 262). All individuals are striving to bring meaning and purpose into their lives through self-awareness and freedom of choice. These core components are exemplified through love and suffering (Frankl, 1963).

Individuals must take responsibility for their life decisions. This ominous sense of responsibility, which is a deciding factor in a person's life, can cause emotional distress. This distress can be defined as existential anxiety. This anxiety occasionally arises "from a personal need to survive, to preserve our being, and to assert our being" (May \& Yalom, 1995 , p. 264). This anxiety is based on an individual's beliefs and feelings concerning death, freedom, isolation, and meaninglessness (May \& Yalom, 1995) as well as on conflicts between moral or spiritual values, or both (Frankl, 1963).

The goal of this philosophy, which founded many humanistic concepts, is to focus on the meaning of the choices a client makes and the consequences that follow. Although humanistic theories borrow greatly from existentialism, they emphasize different directions. Existential counseling is linked to such authors as Frankl and May, who focused on the human condition, view of death, and lack of meaning in life. In contrast, Rogers focused on tapping into one's actualizing potential by providing core relationship conditions, and Perls focused on achieving greater awareness and the integration of disowned parts. Existentialism and humanism were listed separately in the survey to reflect these perceived differences.

\section{Gestalt Theory}

F. S. Perls (1969) and L. Perls (1976) founded Gestalt theory. F. Perls (1969) believed individuals have the capability of bettering themselves through inner wisdom. He proposed that individuals were more than just a sum of their parts. These individuals, in order to become whole, need to integrate, through a phenomenal field, their environment (outer reality) with their needs and emotions (inner reality). This integration of realities eventually leads to a gestalt. Gestalt, meaning the whole, was emphasized in contrast to Freud's focus on an individual's personality from a psychosexual perspective. Because the whole is greater than the sum of the parts, F. S. Perls (1969) and L. Perls (1976) helped to establish a more holistic view of counseling.

F. S. Perls (1969) believed that human beings are capable of functioning in a responsible manner but that problems arise when conflict or anxiety occurs. These problems are caused by an inconsistency between one's inner and outer reality. This conflict leads to a dispute between what is expected 
of a person (idealized self-actualization) and a person's actual inner drive for self-actualization (Nugent, 2000).

F. S. Perls (1969) took a more directive and confrontational role compared with Rogers (Corey, 1996). He believed clients needed to be challenged to get through their phony layers, whereas Rogers used reflective feedback to promote understanding. Both theories seek personal growth through understanding; however, they use different means to the same end. They borrowed from Freud the beliefs that insight is essential and that the counselor-client relationship is significant.

Although humanistic theorists and existential philosophers contradicted Freud's focus on sexuality and reductionism, they were still heavily influenced by psychoanalysis. F. S. Perls (1969) and Rogers (1942) both viewed awareness and understanding as the key elements on counseling. This belief parallels Freud's emphasis on the importance of insight. Humanistic theorists did not believe material was stored away in the unconscious; however, they did state that clients were unaware of core feelings and their meanings. So although the uncovering of insight can be attributed to Freud's influence, yet F. S. Perls and Rogers diverged on the nature of the insight and on the process of gaining insight.

Behaviorism was a bigger step away from Freud's psychoanalysis. From a behavioral perspective, the significance of conditioned behavior takes precedence over insight. Pavlov's salivating dogs, Skinner's trained rats, and Bandura's Bobo Doll experiment all were examples of how people respond to the external as opposed to the internal, according to Corey (1996). Behaviorists attempted to establish a more scientific approach to counseling by focusing on observable actions as opposed to invisible constructs. The primary concept, which is that people are motivated to seek environmental rewards, contrasts sharply with Freud's and Roger's internally focused models. However, contemporary behavioral models have often been integrated with cognitive models to form REBT and other cognitive-behavioral theories. It seems that, with time, internal factors such as cognitive processing have gained greater recognition with behavioral theorists.

\section{TRENDS IN COUNSELOR EDUCATION}

Freeman and McHenry (1996) studied the theoretical models applied by clinical supervisors in programs accredited by CACREP. Their sample of 329 clinical trainers suggested that humanistic theories were well represented in clinical training courses. Freeman and McHenry asked respondents to rate the influence of particular theories in their clinical training class. The results ranked the following theories as most influential to least influential: cognitive and REBT, person-centered, psychodynamic, behavioral, eclectic, Gestalt, Adlerian, humanistic, reality, and feministic. The general humanistic model itself did not rate highly; however, specific humanistic models, such as person-centered, fared very well. 
The results of Freeman and McHenry's (1996) study reflected the three forces in counseling theory. The top-rated theories were cognitive or behavioral, psychodynamic, and person-centered. However, the number of instructors who marked psychodynamic models was fairly small when compared with the humanistic and cognitive/behavioral models. Cognitive and behavioral theories were combined into a cognitive/behavioral category because they are commonly used as an integrated approach. Consequently, it seems that these two approaches, humanistic and cognitive/ behavioral, dominated clinical counseling courses in the mid-1990s. However, it is important to remember the influence that psychodynamic theories had on the development of humanistic approaches.

\section{METHODOLOGY}

A survey instrument was designed to identify the counseling theories taught in master's-level clinical practicum courses in counselor training programs in the United States. Sometimes it is difficult to distinguish a theory from a philosophy. For example, humanism and existentialism are both somewhat vague at the implementation level, although they are influential philosophies. They were included on the survey to be consistent with the Freeman and McHenry (1996) study and also because respondents to a pilot study listed them as a theory used in the practicum course. Sixteen theories were listed on the survey. Inclusion was based on the results of the pilot study and on frequently used textbooks for various counseling theories courses (Capuzzi \& Gross, 1999; Corey, 1996; Corsini \& Wedding, 1996). The survey design was similar to the survey used in Freeman and McHenry's (1996) study on the same subject. The survey was initially tested, as a pilot, on 10 counseling faculty members or master'slevel clinical supervisors before being administered nationally. Respondents could add any theories not outlined on the survey. Basic skills training and generic stage models were named as theories used, although they are not actually specific theories. Basic skills training is defined as teaching counseling microskills without linking them to a particular theory. However, many microskills, such as paraphrasing and reflection of feeling, relate to person-centered counseling so the overlap must be recognized. Generic stage models, also known as developmental stage theories, are defined as approaches to counseling that focus on facilitating the counseling process through a series of stages that are not directly tied to one theory.

A list was obtained that included counseling departments nationwide with at least one program approved by CACREP. Survey packets were mailed to 115 department chairpersons. In an accompanying letter, we asked these department chairpersons to forward the survey to the individual in the department responsible for coordinating the clinical aspects of counselor training if that individual was someone other than the department chairperson. 
We asked respondents to identify the models applied in their clinical training course (practicum). They could indicate as many theories as they wanted, and they could write in a theory not listed on the survey.

\section{RESULTS}

One hundred fifteen surveys were distributed to CACREP-accredited counselor training programs in the United States. Fifty-four usable surveys were returned, which is a response rate of $46 \%$. Among the emphasized counseling models identified by the respondents, basic skills training was identified as the most frequently emphasized model $(n=48)$, followed by person-centered as the second most frequently emphasized model $(n=47)$. Basic skills training obviously is not a counseling theory; however, because it is an approach covered in many practicum classes, it was included in this survey. Jungian $(n=6)$ and generic stage model $(n=10)$ were the least emphasized models. Six respondents chose to list a model other than those listed in the survey. The theories that were added by respondents included interpersonal, narrative, eclectic, solution-focused, family crisis, and feminist. A summary of the counseling models is shown in Table 1.

\section{TABLE 1}

\section{Training Theories and Philosophies Emphasized in CACREP-Accredited Counselor Training Program}

\section{Training Theory}

Frequency

\begin{tabular}{lr}
\hline Humanistic/existential approaches (total for the program = 88) & 20 \\
Existential & 21 \\
Gestalt & 47 \\
Person-centered & 6 \\
Psychoanalytic models (total for the program = 31) & 11 \\
Jungian & 14 \\
Psychoanalytic & \\
Psychodynamic & 42 \\
Cognitive and behavioral models (total for the program = 110) & 27 \\
Cognitive-behavioral & 31 \\
Behavioral & 11 \\
REBT & \\
Multimodal & 48 \\
Other models & 10 \\
Basic skills training & 30 \\
Generic stage model & 27 \\
Adlerian & 26 \\
Brief therapy & 24 \\
Family systems & 6 \\
Reality & \\
Other &
\end{tabular}

Note. $\mathrm{CACREP}=$ Counsel for Accreditation of Counseling and Related Educational Programs; REBT $=$ Rational Emotive Behavior Therapy. 
A humanistic theory (person-centered, Gestalt, or existential) was reported 88 times by the instructor as the type of theory used in the clinical training course. Person-centered counseling dominated the humanistic category, with more tallies than existential and Gestalt approaches combined. Person-centered theory ranked only behind basic skills training as the most frequently applied counseling model taught. Yet, most basic skills relate directly to Rogerian counseling. Eight of the non-humanistic theories were applied more frequently than Gestalt and existential theories.

The group of theories listed as cognitive-behavioral or behavioral was the highest represented group with 110 tallies as an applied model in counseling clinical training courses. The specific cognitive-behavioral classification, with 42 tallies, was rated more frequently than REBT and behaviorism. Lazarus's multimodal theory was rated significantly lower than the other models in this category.

Freudian models were the least represented approaches of the three identified forces of counseling theory. The psychoanalytic and psychodynamic theories both received less than 15 tallies as an applied theory in counseling clinical training courses. The entire category received 31 tallies, which is less than one half of the tallies for humanistic models and less than one third of the cognitive-behavioral and behavioral category. Jungian theory was one of the least listed theories applied $(n=6)$.

Although Adlerian theory overlaps with several other theoretical categories, it is usually identified as a distinct approach in many theory textbooks. This model standing alone was still well represented, with 30 respondents reporting it as an applied theory in their clinical training course. Adlerian theory had only 1 less tally than the entire Freudian-related category combined. Brief therapy $(n=27)$, family systems $(n=26)$, and reality therapy $(n=24)$ also showed considerable influence.

\section{DISCUSSION}

The counseling profession is a young and evolving field (Nugent, 2000). Amidst the competition for theoretical influence, humanistic models are thriving in the early days of the survival-of-the-fittest theories. Although the first half of the century was dominated by Freudian thought, the century ended with two different front-runners in counseling theory, humanistic and cognitive/ behavioral models. The influence of humanistic models is currently very strong in CACREP practicum courses, which suggests that this approach will remain popular in the near future. Person-centered theory was shown to have an especially strong emphasis in CACREP practicum courses. However, existential and Gestalt approaches lagged considerably behind personcentered counseling theory in popularity.

The difference in popularity among these humanistic theories suggests that the influence of all related theories are not equally strong in counseling practica. The existential and Gestalt approaches may not be widely used by counselors 
if they are not exposed to them in practicum. Therefore, the results as a whole show a great deal of support for humanistic theories, although personcentered theory accounted for much of the support.

Another future consideration for the influence of humanistic models is how REBT is classified. A recent movement toward an integrated humanistic model fused with REBT would greatly expand the influence and presence of theories classified as humanistic. The respondents reported that they applied REBT in counseling practica more often than they presented existential and Gestalt theories. Therefore, if REBT is classified as a humanistic approach, the influence of humanistic models greatly increases.

The results of this study supported the findings of Freeman and McHenry (1996) regarding the use of theories in clinical training courses. Personcentered counseling rated as the most frequently taught humanistic approach, and cognitive and behavioral models, along with person-centered theory, accounted for the most theories that were applied overall.

One of the most significant findings, when comparing the results of this study to Freeman and McHenry's (1996) study, relates to the application of brief therapy. Brief therapy was not identified in the prior study; however, one half of the respondents in the current survey stated that they teach the theory in practicum. Brief therapy received more tallies than reality therapy, family systems, and psychoanalytic theory. This trend suggests a recent explosion of interest in time-limited models. Proponents of humanistic theories need to be aware of this trend and consider integrating time-limited components into the existing theories. One question to ask is if counselors promote brief models of counseling because of perceived usefulness or simply as a reaction to the restrictions placed on counselors by health maintenance organizations and the time demands placed on school counselors.

There were several limitations to this study. First, we only surveyed CACREP-accredited programs. Accordingly, the findings cannot be generalized to all counseling programs. Second, about half of the surveys mailed were not completed and returned. Any differences between participating and nonparticipating programs were not accounted for. Third, the theories taught in courses outside of practicum were not addressed in this study. It is possible that theories applied in other courses were not focused on in practicum. Thus, the influence of a particular theory could be stronger than seen in just practicum classes. Fourth, the classification of theories may not adequately distinguish theory from philosophy.

\section{SUMMARY}

Nugent (2000) has identified three forces in counseling theory: (a) psychoanalytic, (b) behavioral, and (c) humanistic. These forces reflect competing ideas on human nature, the goals of counseling, and the nature of therapeutic change. Humanistic counselors can identify trends for the application of humanistic theories by surveying what is being taught to counselors-in-training in practicum 
courses. The purpose of this study was to identify trends in counselor training practicum courses regarding the application of humanistic theories.

Humanistic theories are especially useful in practicum courses because of their focus on relationship variables. Prior research on trends in counseling theory suggested that humanistic theories, especially Rogers's person-centered approach, are frequently applied in counselor training courses (Freeman \& McHenry, 1996). However, cognitive-behavioral models were also highly influential and were found to be the chief competitor to humanistic models. Additionally, Freeman and McHenry found that Freudian theories, although still used, were much less influential than the two other forces in counseling theory.

The current study supported Freeman and McHenry's (1996) results and highlighted some of the more recent shifts in counseling theory trends. In support of prior research, our study found that humanistic theories are frequently applied in counseling practicum courses. Cognitivebehavioral theories were the only other classification of theories that showed more influence. Person-centered counseling was overwhelmingly the most applied humanistic theory. The integrated cognitive-behavioral approach was the only theory applied more than person-centered. Existential and Gestalt theories did not show as much support compared with person-centered counseling; however, the influence of existential concepts permeates Rogerian counseling.

The influence of brief therapy was a major new finding. In this study, brief therapy was ranked much higher than Gestalt and existential theories. This suggests that, as the new century begins, brief therapy models will compete with humanistic theories as one of the major forces of counseling theory.

Hansen (2000) has discussed integrationist efforts between psychoanalysis and humanisim. In light of the influence of brief therapy models, maybe more discussion is warranted on integrating humanism with the time-limited models. However, counselors must keep in mind that theoretical trends should follow empirical evidence showing effectiveness and not simply follow social and political climates in the health industry and in schools.

\section{REFERENCES}

Bernard, J. M., \& Goodyear, R. K. (1992). Fundamentals of clinical supervision. Boston: Allyn \& Bacon.

Brammer, L. M., \& MacDonald, G. (1999). The helping relationship: Process and skills. Needham Heights, MA: Viacom.

Capuzzi, D., \& Gross, D. R. (1999). Counseling and psychotherapy: Theories and interventions. Upper Saddle River, NJ: Prentice Hall.

Corey, G. (1996). Theory and practice of counseling and psychotherapy (5th ed.). Pacific Grove, CA: Brooks/Cole.

Cormier, S., \& Hackney, H. (1999). Counseling strategies and interventions. Needham Heights, MA, Viacom.

Corsini, R. J. (1996). Introduction. In R. Corsini \& D. Wedding (Eds.), Current psychotherapies (pp. 1-14). Itasca, IL: Peacock.

Corsini, R. J., \& Wedding, D. (1996). Current psychotherapies. Itasca, IL: Peacock. 
Frankl, V. (1963). Man's search for meaning. New York: Washington Square Press.

Freeman, B., \& McHenry, S. (1996). Clinical supervision of counselors in training: A nationwide survey of ideal delivery, goals, and theoretical influences. Counselor Education and Supervision, 36, 144-58.

Gladding, S. T. (1988). Counseling: A comprehensive profession. Columbus, $\mathrm{OH}$ : Merrill.

Hansen, J. T. (2000). Psychoanalysis and humanisim: A review and critical examination of integrationist efforts with some proposed resolutions. Journal of Counseling $\mathcal{E}$ Development, $78,21-28$.

May, R. (1961). Existential psychology. New York: Van Nostrand Reinhold.

May, R., \& Yalom, I. (1995). Existential psychotherapy. In R. Corsini \& D. Wedding (Eds.), Current psychotherapies (5th ed., pp. 272-292). Itasca, IL: Peacock.

Nugent, F. A. (2000). Introduction to the profession of counseling (3rd ed.). Upper Saddle River, NJ: Prentice-Hall.

Perls, F. S. (1969). Gestalt therapy verbatim. Lafayette, CA: Real People Press.

Perls, L. (1976). Comments on the new direction. In E. Smith (Ed.), The growing edge of Gestalt therapy (pp. 221-226). New York: Brunner/Mazel.

Rank, O. (1936). Will therapy. New York: Knopf.

Rogers, C. R. (1939). The clinical treatment of the problem child. Boston: Houghton Mifflin.

Rogers, C. R. (1942). Counseling and psychotherapy. Boston: Houghton Mifflin.

Rogers, C. R. (1951). Client-centered therapy: Its current practice, implications, and theory. Boston: Houghton Mifflin.

Yalom, I. D. (1980). Existential psychotherapy. New York: Basic Books.

Diamonds are nothing more than chunks of coal that stuck to their jobs. -Malcolm Forbes (1919-1990), Publisher 